\title{
Should the patient be allowed to die?
}

\section{Richard Nicholson Amersham General Hospital}

In considering the patient's right to a certain quality of dying, this essay outlines how the legal and ethical justifications for passive euthanasia depend on the doctrine of acts and omissions. It is suggested that this doctrine is untenable and that alternative justifications are needed. The development of the modern mechanistic approach to death is traced, showing that a possible basis for an humane way of death lies in a reacceptance of a metaphysical concept of life.

\section{Now death, grown old, is feeble grown and slow Goethe}

If Mephistopheles had cause to complain of the slowness of death in the eighteenth century, one can only wonder at the depths of frustration that he must feel in the twentieth century. With the full armamentarium of modern medical technology ranged against his best endeavours, death truly has become slow; and as doctors all too often 'strive officiously to keep alive', one wonders whether perhaps even Mephistopheles at last feels pity for some of his victims.

Documentation of the protraction of dying by modern medicine, and of the frequently appalling sequelae, has become prolific in recent years, as the problem has itself grown, and most people can now produce their own particular horror stories. The physical origins of the problem lie mainly in the two major medical developments of this century - the control of acute infective illnesses and the development of artificial cardiorespiratory support systems. These developments have led to the situation in which $65 \%$ of deaths are consequent upon potentially long and tedious illnesses - primarily cancer and strokes - and $45 \%$ of deaths are of people over 75 years old; moreover only $35 \%$ now die at home, and of these $37 \%$ had been in hospital for an average of six weeks during the previous year (Registrar-General, 1969: Cartwright et al, 1973). These bald statistics give some indication of the way in which dying has become institutionalized, but it is through case histories that one learns

${ }^{1}$ This essay won a first prize in an essay competition organized by the Medical Defence Union. It is published in a slightly amended form by kind permission of the Medical Defence Union. something of the human effects of this change in $\frac{\mathbb{D}}{\rho}$ the nature of death and dying.

\section{Furor therapeuticus}

John Agate (1973), a geriatric physician, wrote of a patient who came under his care having ' ... had bilateral amputation of the legs at the age of $88,-$ who then immediately after the operation developed is a severe hemiplegia and was rendered speechless? and developed severe pressure sores; then she had a cardiac arrest, and they started the heart again'.

Eliot Slater (1969) has told the story of a friend's? mother-in-law, a 76-year-old sufferer from chronic renal and arterial disease, who had a stroke at home. $\stackrel{\theta}{*}$ Since a doctor could not immediately be contacted ${ }^{\text {Tr }}$ she was rushed by ambulance to a London teaching hospital, where on arrival, she appeared to have breathed her last. Undismaxed, the casualty officer $\bar{O}$ initiated full resuscitation measures, and the lady's heart was kept going for a further 18 hours. $\stackrel{\odot}{\perp}$ Later the casualty officer admitted that no more $\overrightarrow{\vec{A}}$ than a shell of a human being could have remained, $\stackrel{\circ}{3}$ but 'it was not within his discretion to think of $\supset$ what the ultimate issue would be. He had one duty, and one duty only, to do all that lay within his powers to ward off death'.

\section{Quantity not quality of life}

The preceding examples, of what has been described as 'furor therapeuticus', show the way in which 을 doctors may initiate and carry through treatments $D$ that are concerned only with extending the quantity of a patient's life and not its quality. It would be $\bar{N}$ unfair, however, to suppose that the initiative in all ${ }^{\circ}$ such cases comes only from doctors; relatives who $\mathbb{N}$ are unwilling or unable to face the inevitable may $\mathcal{\omega}_{\mathrm{U}}$ take the initiative, as in a case given by Twycross $\mathcal{O}$ (1973). A man of 75 had a laryngectomy for aco carcinoma of the larynx that was unresponsive to $\mathbb{D}$ radiotherapy; a recurrence was also unresponsive $\stackrel{\odot}{+}$ to cytotoxic drugs, and he developed severe $D$ dysphagia. Although the doctors were against it, the $\stackrel{P}{P}$ patient's son insisted that a gastrostomy be per- $\stackrel{\odot}{\Phi}$ formed, and in fact had his father transferred to $\stackrel{\mathbb{Q}}{\mathscr{Q}}$ another hospital where the doctors were willing to 0 operate. The patient became agitated - particularly when he received his four hourly feeds - and slowly응 deteriorated. Two months later, a nurse, who for 
some time had thought that he was trying to communicate something to her, heard him say 'Please no more feeds'. Asked whether he wanted to die, his face changed to a peaceful resignation and he nodded. Three days later feeding was discontinued, the patient became more peaceful, and died five days later.

\section{Definitions of euthanasia}

Most of the occasions on which one may reasonably ask the question, 'Should the patient be allowed to die?' occur in cases such as those given wherein the patient has reached Shakespeare's seventh stage 'Second childishness and mere oblivion, sans teeth, sans eyes, sans taste, sans everything'. But the question may also be asked for two other categories of patient: neonates with severe congenital malformations, and patients who, for one reason or another, are put on to an artificial respirator. In the former category, the problems most frequently discussed are those of whether to perform lifesaving operations on babies with spina bifida and hydrocephalus or other severe neurological deficits, or on severely mongoloid babies with duodenal atresia.

Just as there are several different categories in which the problem of either prolonging life or letting a patient die may arise, so there have been several different solutions suggested. The oldest of these is active euthanasia, while the youngest is humane, and largely drug-based, terminal care; these two solutions also represent the two extremes, amongst the possible solutions, in terms of intervention with the purpose of producing death. Between them lies a spectrum that includes assisted suicide and passive euthanasia.

\section{Active euthanasia}

It would be as well at this point to define the various expressions used above. Euthanasia, literally a 'well, or good, death', may be voluntary or involuntary; it may also be either active or passive, these terms in practice being used synonymously with positive or negative euthanasia. Active, or positive, euthanasia involves the use of treatments designed to promote death sooner than would otherwise be expected. Passive, or negative, euthanasia, is a failure to use therapies that would prolong life in a patient with a terminal illness. Active involuntary euthanasia is indistinguishable from murder but has been actively canvassed from time to time in the forms of amenticide, dementicide, or senicide, in which circumstances patients would of course be unable to give consent. Assisted suicide is an expression used sometimes instead of active voluntary euthanasia. As the law stands at present any physician involved in such an activity could be deemed to have committed murder; thus it has been this type of euthanasia that the proponents of the 1936 and 1969 Voluntary Euthanasia Bills have been trying to legalize.

\section{Passive euthanasia}

Passive euthanasia, on the other hand, has not been thought of as direct killing, and so has found considerable favour amongst those who are trying to solve the problems of the prolongation of dying that have been outlined. The approach of institutions such as St Joseph's and St Christopher's Hospices has been to treat palliatively both the physical and mental symptoms of their patients with terminal illnesses. Much attention has been paid to the skills that they have developed in successfully controlling pain; but their achievement in being concerned for the total welfare of their patients and their attention to detail are just as important for patients. It is not unreasonable to suggest that one sees in these hospices a more humane medicine being practised than anywhere else in the country (Twycross, 1973; Saunders, 1970).

It is at this point, however, that one comes up against the first difficulty caused by the definitions that have been attempted. There are many who would deny that there is any element of euthanasia in good terminal care; they would claim that any protraction of the process of dying is clinically, and possibly ethically, bad practice and that good terminal care is merely the process of allowing patients to die comfortably. Moreover, their attitude is that to say that there is 'nothing more to be done', as Smithers (1970) has pointed out, is 'inexcusable and seldom, if ever, true.' It is difficult, however, to see any difference ethically between the notions of good terminal care and passive euthanasia, particularly when contrasted with the practice of $\frac{5}{3}$ doctors such as that quoted by Eliot Slater on page 5, and so for the rest of this essay they will be $\frac{0}{3}$ treated synonymously.

Nevertheless the approach, inherent in good 은 terminal care, to the problems that were originally $\frac{D}{O}$ outlined seems to offer the best hope of satisfactory solutions. It is by no means certain that it is any $N$ more reasonable ethically than would be active voluntary euthanasia. There are those doctors who 0 say that anything less than complete striving to keep $\mathrm{\omega}$ alive may be regarded as killing, and their approach to practical problems obviously differs markedly 0 from that of advocates of passive euthanasia. This $\mathbb{D}$ difference was shown well at a conference in 1973. when two paediatric surgeons were discussing their $\frac{T}{T}$ approach to the problems of whether or not to treat $\frac{\vec{D}}{\mathbb{D}}$ spina bifida babies. Both selected babies for operation; but their treatment of those left un- $\mathbb{Q}$ operated upon differed considerably. Eckstein said $\overline{2}$ 'I think that we have a moral duty to the family to 8 ensure than an untreated baby survives for as short a time as possible .... Over the past year or so we 
have had a $100 \%$ mortality within the first four weeks of life in those infants whom we decided not to treat actively (1974).' Zachary, on the other hand, said: 'The purpose of this selection of cases not to be operated on is not that the child should die... it is to my mind a clinical decision that I see no advantage in the operation. The attitude, that a deformed baby should be allowed, or encouraged, or persuaded to die, is likely to mean that the doctor will be constantly looking for opportunities for the child to die in the neonatal period' (Zachary, 1974).

But it is not only those who take such an absolutist stance who may have to reject passive euthanasia as being ethically unacceptable. There has in fact been in the medical profession a remarkable unwillingness to examine thoroughly the ethics of passive euthanasia.

The earliest attempts to justify the approach seem to have been made at the start of this century, and to have consisted primarily of ritual incantations of:

Thou shalt not kill; but needst not strive Officiously to keep alive.

This is taken from Arthur Clough's poem The Latest Decalogue written, in 1860 , entirely as a parody of the way in which the Ten Commandments were being disregarded. The poem in fact continues:

Do not adultery commit;

Advantage rarely comes of it;

Thou shalt not steal; an empty feat,

When it's so lucrative to cheat.

It is surely rather strange that we have not heard hundreds of local government officials recently quoting the second couplet above to justify their corrupt activities. The origin of the misappropriation of the 'Thou shalt not kill' couplet would appear to be its use out of context by Bernard Shaw in the last act of The Doctor's Dilemma. But even there he is using it in its correct sense to point up the cynicism of the physician Ridgeon, who has allowed the artist Dubedat to die so that he might marry the widow.

\section{Doctrine of acts and omissions}

More recently various attempts have been made to justify passive euthanasia both legally and ethically. Though they may do so by varying paths, these attempts almost without exception end up relying on the 'acts and omissions' doctrine. This states that in certain contexts failure to perform an act, with certain foreseen bad consequences of that failure, is morally less bad than to perform a different act which has identical foreseen bad consequences; ie, it is worse to kill someone than to allow them to die; or, passive euthanasia is less reprehensible than active euthanasia.
Before considering whether this doctrine is tenable, it is worth pointing out the ways in which $\varrho$ various approaches rely on it. Since Pope Pius XII's pronouncement in 1957 in which he argued that there is no absolute obligation to employ any means which involve a grave burden for oneself or others, the Catholic Church has accepted a closely defined view of passive euthanasia. Häring (1972) makes the point that passive euthanasia is to be formally rejected if the concept is unduly enlarged, and if considerations of bare utility enter into the picture,' thus almost entirely precluding the Pope's allowance for 'grave burdens'. Pope Pius's pronouncement $\vec{\circ}$ depends on the distinction between the use of $\overrightarrow{\vec{\omega}}$ ordinary and extraordinary means, and sanctions the omission to use extraordinary means, thus effectively reverting once more to the acts and omissions doctrine. It does not in practice give any guidance to the doctor, being concerned with ir treatments rather than patients, and leaving it to his $ᄋ$ discretion to decide what is ordinary and what is not. A simple example, given by Campbell (1972), $D$ that of antibiotics, serves to illustrate the problem; they must surely now come into the category of $\overrightarrow{\vec{\theta}}$ ordinary means, but does that imply an obligation to use them in the patient with carcinomatosis who develops bronchopneumonia?

The Church of England has tacitly accepted the validity of the acts and omissions doctrine without the caveats of the Catholics. Quoting a similar example to that of Campbell, Dunstan (1972) says 'To withhold the antibiotic on the principle of proportion or of relevant treatment, is not, I suggest, the moral equivalent of deliberately putting someone to death'. Likewise the former Archbishop of Canterbury: 'Where a patient is lingering on in great distress, without any possibility of continuing life or happiness or purpose, it is not necessary for the doctor to continue keeping him alive' (Times, I97I).

\section{The legal position of passive euthanasia}

The legal position of passive euthanasia is somewhat difficult to assess since it has never been tested in the $N$ courts. Glanville Williams (1973), however, finds it readily acceptable 'because, although withholding the means of life for the purpose of death and in breach of duty is murder, the duty to supply the means of life is not coextensive with the duty not to $O$ kill'. G P Fletcher (1969) looks at the applicable elements of common law murder: $I$ ) an act resulting : in death, 2) an intent to inflict death, 3) malice 0 aforethought, 4) absence of defences. The second $\underset{\mathbb{D}}{\stackrel{O}{(}}$ condition is obviously present, and since the legal concepts of malice and motive are somewhat at $\stackrel{\mathbb{Q}}{\circ}$ variance with strict lexicographic meanings, the $\underset{2}{ }$ third would also be present. The only possible $?$ defence would be that of necessity, and it is hard to imagine any circumstances in which all the criteria

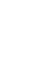


for such a defence could be satisfied (Paley, 197I). One is left therefore with the only possibility of defence resting on whether there was an act resulting in death, and again one is drawn back to the distinction between acts and omissions. In fact, Fletcher admits that 'upon analysis, we find that our thesis for distinguishing acts from omissions survives only in part: it works for some omissions, but not for others'; but by referring to the concept of duty, as had Glanville Williams (1973), he suggests that the thesis remains intact in the case of a physician permitting a patient to die.

\section{Rejection of the doctrine of acts and omissions}

Jonathan Glover (1972) has argued forcefully that we should in fact reject the acts and omissions doctrine, even though at first sight this would appear to have some dire consequences. He considers the sources of strength of the doctrine, and concludes that they are largely derived from four confusions: I) confusion between varieties of omission leading to difficulty in distinguishing an act from an omission; 2) confusion between the doctrine and that of negative utilitarianism; 3) confusion between direct and side effects; and 4) confusion between the standpoints of moral judge and moral agent. The only conclusion that may be drawn from his lucid and appositely illustrated examination of the doctrine is that there is in fact no good evidence to support it. There are those who would argue that it must be retained since the consequences of its rejection would be too dangerous, and this is implicit in the legal conclusion formulated by G P Fletcher (1969). It might be said that the result of having to regard failure to keep alive one's centenarian relative as being on the same level as murder would be to make one more willing to kill. This style of reasoning invites the reply from Hume quoted by Glover: 'There is no method of reasoning more common, and yet none more blameable, than in philosophical debates to endeavour to refute any hypothesis by a pretext of its dangerous consequences to religion and morality. When any opinion leads us into absurdities: 'tis certainly false; but 'tis not certain an opinion is false because 'tis of dangerous consequence.'

The 'dangerous consequence' of the foregoing argument is that passive euthanasia must be regarded as being ethically no different from active euthanasia; it reinforces the conventional but somewhat imprecise concept of the sanctity of life, and it causes grave doubts as to the morality of what is regarded as good terminal care. How then may one reconcile what one regards as remarkably humane medical care with the prospect that the result of that care is unethical? A possible answer lies in a consideration of society's attitudes to health and to death, and of the ways in which they have changed in the past.

\section{Classical attitudes to life and death -}

The ancient Greeks were well aware of some of the problems of prolonging life. Socrates in particular demonstrated in the Phaedo the difference between life as a biological process that may be prolonged as far as possible, and life as a spiritual pilgrimage that must be undertaken in a dignified manner. When Socrates asks the executioner to bring his cup of hemlock, Crito urges him to wait: "The sun is still upon the hilltops, and I know that many a one has taken the draught late, and after the announcement has been made to him, dines and drinks well and sometimes enjoys some love he desires; do not hurry - there is time enough'. To $\Phi$ which Socrates replies: 'And those whom you $\overrightarrow{\vec{C}}$ speak of, Crito, naturally do so; for they think that ir they will be the gainers by so doing. And I naturally $\mathrm{O}$ shall not do so; for I think that I should gain nothing by drinking the poison a little later but my $\rightarrow$ own contempt for so greedily saving up a life which is already spent.'

Socrates' immensely reasonable manner was no ov doubt dependent on his belief in the Orphic doctrine, that he had earlier expounded, of the two-fold nature of man - temporal body and immortal soul.

Within a couple of centuries, the Stoics and Epicureans had made suicide into the most reasonable and desirable way out of life, and painful $\overrightarrow{\vec{O}}$ disease or any other intolerable constraint was 3 reason enough to commit it (Alvarez, I97I). But their attitudes must in part have been a reaction to a life in Rome that was unspeakably wanton, corrupt, and cruel: as Alvarez suggests: 'Stoic $\Phi$ dignity was a last defence against the murderous squalor of Rome'.

The Roman indifference to death was carried over into early Christian teaching: from the viewpoint of a Christian heaven, life to the early Fathers 9 appeared unimportant or evil. Since martyrdom $\frac{D}{0}$ offered not only forgiveness of sins, but also posthumous glory, it became more and more $N$ actively canvassed, until St Augustine, so disgusted with the activities of the Donatists, argued so $N$ forcefully against suicide that it became the most $\mathrm{\omega}$ deadly of mortal sins. This attitude still lingers on, so that suicide - even as a result of painful disease - $Q$ is regarded either as a moral crime, or as a clinical $\Phi$ disease that may be reduced to statistics, but from + which all consideration of the human agony has ${ }^{\circ}$ been removed.

From that time until the late Middle Ages it was $\cong$ Hell that kept people in fear, not death. The Dance $\stackrel{\square}{\perp}$ of Death was originally with man's mirror image Death was the true end, more certain even than immortality (Illich, 1973). But then in the paintings of Holbein the younger, and others, the mirror

.

Hold


image became a skeleton man, and Death had become a force of nature, which man wanted to master by learning the art of dying. For Paracelsus dying was a struggle, between bitter, dreadful Death and nature herself, that did not exclude a belief in transcendence, but allowed the body to be reduced to an object. For Bacon it became permissible to regard the prolongation of life as one of medicine's tasks, though Montaigne in 1580 could still ridicule the idea of death in old age as 'an idle conceit.'

\section{- and modern attitudes}

From then on, however, the social demand for longevity increased, bringing with it the turning of attention from the sick to the sickness. Simultaneously the effort to reduce metaphysical terms and matters to mechanical ones following the Newtonian - Lockean - Cartesian view reduced man to a palimpsest (Sachs, 1973). Thus man has lost the image of an afterlife, which in its Orphic picture allowed Socrates the possibility of dying in a dignified manner, and has ended - like Camus 'with an affirmation of individual life, in itself and for itself, desirable because it is 'absurd', without final meaning or metaphysical justification' (Alvarez, 1971). But modern medicine increasingly dismisses even our individual existence, seeing our diseases as bad and alien, with no relation to the ill person, requiring therefore that one attack the disease with all possible weapons, without a thought for the person who is ill.

\section{Practising a humane medicine}

Our only possibility of practising a humane medicine, in which it is not only ethically acceptable to allow the patient to die but in which there is an ethical imperative to sanction passive euthanasia, must lie in a reacceptance of the metaphysical approach to nature. And, as Leibniz stresses, the metaphysical approach precedes the mechanical: the world's mechanics subserve its design. Perhaps then we shall once more be able to meet death, and the end will not come, in J Fletcher's words
(1973), for patients 'while comatose, aerated, betubed, glucosed, narcosed, sedated - not conscious, not even human any more'. Rather may we die with the dignity of Socrates, whose last words were a reminder to his friends to make a sacrifice to Asclepius, the god of healing.

\section{References}

Agate, J (1972). Contact 38, Supplement. Edinburgh. Alvarez, A (1971). The Savage God. London.

Campbell, A (1972). Moral Dilemmas in Medicine. Edinburgh.

Cartwright, Ann, Hockey, Lisbeth, and Anderson, John L (1973). Life before Death. London.

Dunstan, G (1972). Contact 38, Supplement. Edinburgh.

Eckstein, H (1974). Spina bifida, the surgeon's responsibility. Documentation in Medical Ethics, 3.

Fletcher, G P (1969). In Euthanasia and the Right to Death, edited by A Downing. London.

Fletcher, J (197I). The Right to Live and the Right to Die. Vesper Exchange.

Glover, J (1972). Not striving to keep alive. Documentation in Medical Ethics, $\mathbf{I}$.

Häring, B (1972). Medical Ethics. London.

Illich, I (1973). On the political uses of natural death. A CIDOC seminar paper. Cuernavaca.

Paley, J (197I). Compulsion: fear and the doctrine of necessity. Acta furidica.

Pius XII (1957). Acta Apostolicae Sedis XXXXIX.

Registrar General (1969). Statistical Review of England and Wales, 1969.

Sachs, $O$ (1973). Awakenings. London.

Saunders, C (1970). In Matters of Life and Death, edited by E F Shotter. London.

Slater, Eliot (1969). In Euthanasia and the Right to Death, edited by A Downing. London.

The Times (1971). 3rd May.

Twycross, R (1973). A plea for euthanatos. Documentation in Medical Ethics, 2.

Williams, Glanville (1973). Euthanasia. Medico-Legal fournal.

Zachary, $R$ (1974). Attitudes to the abnormal child. ON Documentation in Medical Ethics, 3. 